VÁR I O S 


\title{
D. CATARINA DE BRAGANÇA, PERSONAGEM HISTÓRICA $X$ CATARINA, FIGURA FEMININA
}

\author{
Maria Antonieta Amarante de Mendonça Cohen \\ Universidade Federal de Minas Gerais
}

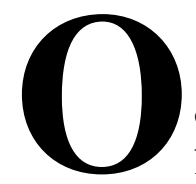

trabalho que ora apresentamos integra pesquisa em desenvolvimento sobre a correspondência de Catarina de Bragança - nobre portuguesa do século XVII, da dinastia de Bragança, que veio a ser rainha da Inglaterra. Discorreremos aqui sobre parte dessa correspondência: o manuscrito inédito guardado no Departamento de Manuscritos do Museu Britânico, localizado por nós em 1983. Uma outra recognitio do manuscrito foi feita em 1997. Consiste de cartas escritas em português por Catarina de Bragança, rainha de Inglaterra a seu irmão D. Pedro II, rei de Portugal, na $2^{\text {a }}$ metade do século XVII. Catarina era filha de D. João IV, da casa de Bragança, rei de Portugal e de D. Luíza de Gusmão. Em 1662 desposou Carlos II, 3ำ monarca da casa de Stuart de Inglaterra, e é já como rainha que escreve as cartas a seu irmão. Referência a este manuscrito foi encontrada em um catálogo na sala de Manuscritos do Museu Britânico: o Catálogo dos Manuscritos Portugueses ou relativos a Portugal existentes no Museu Britânico, de Pedro Tovar, datado de 1932, Coimbra.

Constitui-se de 176 fólios, dos quais 88 são cartas, assim distribuídas: 84 são autógrafas de D. Catarina a seu irmão D. Pedro II; duas de D. Pedro, endereçadas a D. Catarina; e duas do Padre Manoel Diaz, conselheiro da rainha, endereçadas a D. Pedro. Abrindo a coletânea, datadas de 1851, redigidas em francês, há 
informações sobre o documento e sobre circunstâncias históricas da vida de D. Catarina, escritos, possivelmente, pelo $1^{\circ}$ colecionador das cartas ou por Francisco de la Figanière, autor de um dos catálogos consultados.

A problemática das cartas deverá ser a do tratamento das correspondências e não a do tradicional gênero "epistolar".

Caracterizam-se as cartas em questão como "cartas missivas". Segundo Laufer (1980), as cartas missivas distinguem-se das epístolas por terem um destinatário real. Na epístola, a forma "carta" é usada para fins literários públicos. No presente caso, as cartas são de caráter privado, todas autógrafas de D. Catarina, endereçadas a D. Pedro II, seu irmão, configurando, pelo menos na intenção, a "situação de comunicação" a que se refere Laufer. Segundo este (op. cit.: 83), "a correspondência se acha invariavelmente numa situação de comunicação." Também Roger Pierrot, editor da correspondência de Balzac, afirma ser a correspondência um diálogo, apesar de reconhecer que "nem sempre é fácil encontrar a missiva e sua resposta." (op. cit.: 84). Inserem-se, portanto, neste estudo, as cartas (apenas duas) endereçadas por D. Pedro a D. Catarina, que se encontram no códice investigado. Neste caso, principalmente, a inserção das pretensas "respostas" revela-se pertinente, pois, como se verá, as cartas eram censuradas, como a própria Catarina nos informa, e existe a possibilidade de que muitas delas não tenham chegado ao seu destinatário. Nesses casos, a situação de diálogo não teria se configurado, mas a de monólogo.

O estabelecimento do texto (decifração e transcrição dos manuscritos) propriamente suscitou poucas questões, uma vez que as cartas são autógrafas em uma única versão, trata-se de um codex unicus: a questão da autoridade do documento não se coloca. Sua ordenação cronológica (datação) é etapa importante, bem como a notação e a pontuação. A análise lingüística pretende ser uma contribuição para a descrição da sintaxe portuguesa do século XVII, 
tão pouco conhecida pelos especialistas na história da língua portuguesa. $^{1}$

Abordaremos preliminarmente as cartas de acordo com seu aspecto formal, material e de acordo com aspectos que denominamos internos, ou esclarecedores do conteúdo, de uma maneira fenomenológica.

\section{I - Aspecto formal/material}

- Volume encadernado com a borda das folhas levemente douradas, em excelentes condições de manuseio e leitura.

- Letra: boa caligrafia, melhor e mais legível do que a de D. Pedro;

- Há uma síntese do conteúdo de cada carta no verso da mesma, ou à sua margem, com duas caligrafias diferentes. Serão de sua mãe, como o sugere o autor da introdução acima, ou de Francisco de la Figanière, que certamente as leu? Além das cartas autógrafas, revela-se, assim, no próprio documento, a presença de três de seus leitores posteriores: o que fez a introdução e os dois autores das sinopses e numeração das cartas (há duas numerações, com caligrafias diferentes). A partir da carta de $\mathrm{n}^{\circ} 70$, a primeira numeração é riscada, e a carta renumerada. Há, por exemplo, duas cartas de $\mathrm{n}^{\mathrm{o}}$ 110. A partir da carta 52, os resumos vêm com outra caligrafia, quase ilegível.

- Há de quando em quando alguns lacres. Há também carimbos do Museu Britânico e das armas reais, posteriores à época em que as cartas foram escritas.

- As páginas apresentam manchas cor de vinho desbotadas que muitas vezes dificultam a leitura no original e em duas ou três há

${ }^{1} \mathrm{Na}$ edição, em elaboração, dessas cartas, as formas lingüísticas serão mantidas como se apresentam, com o máximo de fidelidade possível ao original: as abreviaturas serão mantidas, como também os "espanholismos" e outros aspectos relevantes para posterior análise lingüística. Somente grafismos sem nenhum significado lingüístico serão alterados, se necessário. 
marcas que nos pareceram ser de lágrimas. Quando da leitura dos originais, não tivemos dúvida quanto à natureza dessas marcas. No microfilme com o qual trabalhamos agora (diapositivo de 35 mm.), fica mais difícil sua identificação. Um outro reconhecimento do manuscrito será feito, para que se decida sobre a natureza dessas manchas.

\section{II-Aspectos internos (esclarecedores do conteúdo)}

\section{a - Contextualização histórica}

O casamento de Catarina da casa de Bragança com Carlos II, $3^{\circ}$ monarca da casa de Stuart, data de 21 de maio de 1662. Casaramse, primeiro, secretamennte, segundo o ritual católico e, em seguida, segundo o ritual protestante na igreja de "Domus Dei", em Portsmouth, Inglaterra. O casamento foi parte de um tratado entre os dois países, quando se restaurou a monarquia na Inglaterra após onze anos da "república" de Cromwell - e resolveu os problemas financeiros de Carlos II, até então exilado e tentando reaver seu direito ao trono. Ao embarcar a infanta, segundo Livermore (1947) e outros historiadores, esta leva de dote um milhão de cruzados (correspondentes a 300.000 libras), e outro milhão após um ano. Carlos II recebe de Luís XIV de França 300.000 pistolas francesas o que corresponderia a 3 milhões de francos. Pelo fato de Catarina ser católica, o casamento foi visto com bons olhos pela mãe de Carlos II - a rainha-mãe -, a francesa Henriqueta Maria, filha de Henrique IV, também católica, que vivia em França. Além desse dote, Inglaterra recebia Bombaim e Tânger, dois pontos estratégicos importantes, e comércio livre no Brasil - na Bahia, Pernambuco e Rio de Janeiro -, e na Índia - em Goa, Cochim e Diu. Em troca, Catarina teria liberdade de credo e Portugal teria reforço por mar e terra em caso de ataque por parte da Espanha ou Holanda.

A aliança foi, portanto, vantajosa para a Inglaterra, que, segundo consta, nunca ofereceu real proteção a Portugal, tendo a 
corte inglesa abertamente hostilizado a rainha católica, chegando a mesma a ser injustamente denunciada ao Parlamento sob a alegação de armar uma conspiração para matar o rei e os católicos tomarem o poder, por volta de 1678. A Casa dos Comuns chegou até mesmo a afastá-la de Whitehall e pensou-se em mandá-la diretamente para a Torre de Londres, prisão onde se praticaram crimes hediondos. Somente por interferência do próprio rei pôde livrar-se Catarina das falsas acusações.

A contextualização histórica envolve o problema da cronologia/datação das cartas. Catarina as data de forma incompleta. Em algumas coloca o mês e dia, mas não o ano, como, por exemplo, a carta 42, que é de 28 de outubro, e a 37, de 20 de janeiro. Em apenas uma coloca o ano, a de $\mathrm{n}^{\mathrm{o}}$ 105: 1690. Às vezes, conclui a carta datando-a assim: "oje, 12 de fevereiro", como na carta 17, ou na carta 42: “oje, 28 de outubro". Sabe-se, por fontes históricas, que Catarina casou-se com Carlos II em 1662 e que retornou a Portugal 30 anos depois, 1692. As cartas foram escritas dentro desse espaço de tempo, a maior parte delas, de Londres: começam com um L maiúsculo, e algumas têm a especificação da residência de Catarina: ou Somerset House, que ainda é uma das residências reais em Londres, ou Windsor. Algumas poucas cartas são da França, e uma de Almeida, Portugal, certamente uma das últimas, já na tão esperada viagem de retorno à sua terra natal. Há uma tentativa de datação em três delas, por algum de seus leitores: uma possivelmente de 1682, isto é, 20 anos após sua chegada à Inglaterra, uma de 1688 e outra de 1692. As de Manoel Diaz são ambas de 1688 e uma das de D. Pedro, de 1689. É relevante que se associe o conteúdo histórico das cartas aos fatos comprovadamente históricos, para que se esclareça o problema de sua cronologia.

Acreditamos que a tentativa de renumeração das cartas feita por um de seus leitores teve a finalidade de atribuir-lhes uma ordenação cronológica, mas esta será alterada neste trabalho. 


\section{b - Teor das cartas}

Chegamos agora às próprias cartas. Qual é o seu teor? Qual é o seu tom? Elas soam, aos meus ouvidos, basicamente como um lamento. Catarina repetidamente fala de sua falta de alegria, do desgosto de viver em uma sociedade hostil e de sua falta de saúde decorrente de tanto desgosto. Identificam-se também outros dois temas: o pedido que faz repetidamente ao irmão para que a leve de volta a Portugal; seu afeto/amor por ele, que carregou em seus braços, e a dependência que demonstra por notícias dele. No nosso entender, Pedro representa, metonimicamente, para Catarina, tudo de bom que ela deixou em Portugal - a sociedade católica, os afetos familiares, a folga de dinheiro, ou seja tudo o que ela não tinha na corte inglesa, e a esperança de uma vida melhor. Esta ansiedade torna-se clara através da maneira como inicia e conclui as cartas. Além desses aspectos, que constituem uma quase-imobilidade temática, Catarina refere-se também a fatos históricos, demonstrando conhecimento dos problemas políticos, diplomáticos e religiosos que a circundavam.

As cartas eram censuradas, o que é abertamente colocado por ela: sua postura política não é, portanto, apresentada nelas, e circunscreve-se mais no âmbito do "não-escrito". Na carta 52 ela diz claramente "... q' nenhũa carta vai sem exame...", no seguinte contexto: já que nenhuma carta vai sem exame não darei notícias detalhadas. Também nesta passagem, da carta 26 , notamos que ela não quer dizer abertamente alguma coisa: “... eu espero vos não estareis tão esquecido de mi q' não entendais o q' eu dezejo..."

Veja-se também a carta à pág. 26: "so a execução emcomendo que seja acellerada por rezões particulares, que são mais para comunicadas que escritas..."

Há três ou quatro cartas mais leves, em que pede apenas notícias de Portugal e do rei seu irmão, reiterando seu afeto por ele. Essas são, no nosso entender, cronologicamente as últimas, em que ela já está em sua jornada de volta a Portugal. São as seguintes: a de $n^{-}$16, de Mullins, na França, e as de número 8 e 66, em que 
brevemente solicita novas de de seu irmão. Nessas Catarina demonstra alegria, nas suas próprias palavras "alvorosso", que também aparece em uma ou outra carta em que menciona ter recebido notícias de D. Pedro depois de longo silêncio.

Há duas em que refere-se ao marido, Carlos II, de forma respeitosa, dizendo "Do affecto e demonstrações de empenho Del Rey para commigo".

Observemos alguns desses excertos, por tema, a saber: lamento/tristeza; desejo de retornar à pátria; afeto/amor pelo irmão; referências afatos bistóricos.

\section{1) Lamento/tristeza}

- Carta 72: “...Novas minhas não são as que vós desejais pois as da saude he muy imperfeita e as do gosto ainda mais diminuto, e nao se pode esperar outra couza, adonde a Igreija, está tao opprimida, como aqui de prezente..."

- Carta 4: “...não mos diminuindo a grande violencia q' a mi mesma me faço vivendo aqui... eu me seguro de melhor rizulução q' a de me ver aqui no perigo em que a minha vida se acha... asi por falta de gosto como por o clima..."

- Carta 40: “...as novas q’ eu de mi posso vos dar são mui breves, q' quem não tem gosto, não pode ter saúde, e como os Annos crecem fazem tudo mais dezabrido."

- Carta 50 (que mantém este tom do princípio ao fim): “...pois he o tempo q' vivo o q' fallo com vosco..."

- Carta 42: “...o gosto não he nem pode ser muito, D’s o sabe ...estou tão desconsolada, q' não posso passar daqui..."

\section{2) Desejo de retornar à pátria: súplicas $\mathrm{a} \mathrm{D}$. Pedro}

- Carta 24: "A minha esperança está em vos me aliviardes desta penna, mandandome embaixador, que faça os meos e os vossos negocios, para me ver comvosco..." 
- Carta 21:

... me aveis de defferir com toda brevidade comforme ao meu dezejo, e ao que meu Amor vos merece, e como este e tão grande e agigantado ficão lhe as esperanças mui seguras de que vos não detereis em cooperardes comigo em hũa couza tão facil como justa. Lembraivos que eu não tenho de minha parte faltado, despois que me faltou El Rey de vollo pedir, despois varias vezes tenho instado, ultimamente muitas por escrito...

- Carta 28:

... e se não me derdes o gosto de querer q' eu vos veja, q' e o tudo ao q' a minha consolação aspira, respondeime ao q' vos q' avendo aqui riscos de vida, q' parte do mundo ai para mi mais propia q' a minha patria, donde tenho hũ Irmão Rey e amante, negandome vos isto vede q' adonde buscarei Proteção...

\section{3) Afeto/amor pelo irmão}

- Carta 1: “... se tem o Amor de hua Irmãa que vos criou em seus braços..."

- Carta 33: "Meu Irmão. Se o gosto q' tive com hua vossa de 9 de dezembro me não acaba de restituir de todo a saude..."

- Carta 28: "Meu Irmão. Estando para vos fazer esta, se me duplicão as razões pois a primeira e a principal para mi, he sempre o dezejo de boas novas vossas..."

- Carta 21: "Meu Irmão. Dezejando sempre novas vossas, agora as espero co muyta mayor impaciencia..."

Através do fecho das cartas, mesmo dentro dos limites impostos por esta forma, muitas vezes repetitiva, Catarina expressa seu afeto pelo irmão. Observem-se:

- Carta 17: "I mº Amante C" ("irmã muito amante, Catarina")

- Carta 8: "I' toda V C" ("irmã toda vossa, Catarina")

- Carta 6: "Irmãa Amiga" ("irmã amiga")

- Carta 4: "I Amantissima C" ("irmã amantíssima, Catarina") 
- Carta 1: "Irmãa q' vos Ama com todo seu coração" ("irmã que vos ama com todo seu coração")

- Carta 132: "Desconssolada e Afflicta mas sempre Amante C" ("desconsolada e aflita, mas sempre amante, Catarina")

\section{4) Referências a fatos históricos}

- Carta 1: "Aqui vos representou o residente de Saboya q' da p te $^{\text {de }}$ Madame Real q' o Duque, despois de sair da minoridade retificara o contrato, nova q' $\mathrm{m}^{\text {to }}$ estimamos."

- Carta 6: “...no tempo prezente, em q' o mundo todo arde em guerras..."

- Carta 17: "Vai Gaspar de Abreu e deixa nesta corte $\mathrm{m}^{\text {to }}$ bom nome, pollos bons termos com q' se houve com todo... deixo o fazervos prezente o estado dos negocios no tempo prezente e o q' se pode temer com a vinda do parlamento q' sera $\mathrm{p}^{\mathrm{a}}$ os 19 de Abril q' vem..." (1879?)

- Carta 48: "Navios, só em hũa noute se perderão dous Inglezes e hũ ollandes de 60 e 70 peças."

- Carta 53: “Aqui estamos todos as escuras, sem noticias nehuas q' os francezes fazem, o q' pa elles, este Rey, daqui intentava, pois era tratar, com os seus Alliados sem q' el Rey de França soubesse dos seus tratados..."

\section{c - D. Catarina de Bragança - personagem histórica X Catarina - figura feminina}

Catarina, desde o início das negociações de que seu casamento fez parte, teve opositores: holandeses e espanhóis, a quem a aliança Inglaterra/Portugal não favorecia, foram os primeiros. Estes enviaram a Carlos II informações tais como as que se seguem: Catarina era feia, defeituosa e doente. Foi preciso que os intermediadores da aliança enviassem um retrato da infanta para que Carlos II se decidisse. De acordo com o testemunho deste, quando a viu pela primeira vez (Cf. Pearson, 1960), "ela não é o que se pode chamar uma beldade, mas 
não há nada em sua aparência que possa chocar ninguém, pelo contrário, ela é uma figura agradável, como ele jamais tinha visto, tinha graça, boa conversação, e uma voz agradável”.

Foi chamada por outros de "a feia triste" e de "antipática, sovina e inculta”, principalmente em publicações sobre a monarquia inglesa. Além de toda esta fama não deu filhos ao rei, era católica e ao casar-se não falava inglês. Parece que sempre se comunicou com o marido em espanhol. Ou seja, tinha todos os requisitos para desagradar à corte inglesa.

Carlos, por seu lado, era mulherengo, e quando casou-se com Catarina já tinha amantes de longa data, como a famosa Lady Castelmaine. A vida, em sua corte, parecia mais egípcia do que inglesa. Seguia os hábitos franceses e influenciava a todos, até no detalhe de as mulheres usarem lacres em suas cartas maiores do que os habituais ingleses. O flerte, o jogo, eram incentivados à sua volta. Foi o "Merry Monarch". Teve quinze filhos bastardos, de diversas mulheres e a todos reconheceu como seus. Dentre as amantes houve sempre as preferidas, que fazia serem damas de honra da rainha D. Catarina, como as famosas Lady Castelmaine e Nell Gwynn, estas muito mais ao agrado da corte inglesa do que a católica Catarina.

Conta a história que Catarina sempre amou o marido e que acabou por aceitar a realidade de sua vida conjugal: a presença das amantes de Carlos na corte e sua vida sem prestígio, abafada pelas "mistresses", no que toca à beleza e sexo.

No entanto, há testemunhos de que se interessava por teatro, tendo representado peças de Sheakespeare. Jogava cartas, tendo sido também exímia jogadora de arco e flecha e patronesse do "Honorable Company of Bowmen", cujo brasão consistia nas armas da Inglaterra e a legenda "Reginae Catharinae Sagitarii". Introduziu na corte inglesa o hábito de se tomar chá.

As cartas são silenciosas quanto aos aspectos referidos acima: nelas o mis-en-scene de Catarina é o de uma irmã afetuosa, amorosa, delicada; uma rainha oprimida, injustiçada, discriminada, perseguida, encarcerada e, conseqüentemente, doente, cuja razão de viver 
era a esperança de retorno à sua terra natal. Depreende-se, no entanto, através das referências a fatos históricos, que Catarina não era desinformada a respeito da situação política que a circundava e que desenvolvia atividades. Na carta 1 (1682?), por exemplo, ela diz que está se empenhando em cumprir as obrigações de que ElRey, seu marido, a havia encarregado. Por sua caligrafia infinitamente melhor que a de seu irmão D. Pedro - e conteúdo das cartas, não se comprova a "falta de educação" a ela atribuída: tendo sido educada em um convento, certamente teve boa instrução e educação católica rígida.

Até esta altura da nossa investigação, vimos emergir das cartas duas figuras: a de Catarina, figura feminina, amorosa, nos seus próprios termos "amante", sensível, e a de D. Catarina, a rainha, mulher política e religiosamente atuante.

A relação entre as duas Catarinas se tornará mais clara a partir da análise lingüística do documento que ainda não foi levada a cabo. Se acreditarmos no título dado a um artigo publicado por um estudioso da correspondência de Freud, As cartas não mentem jamais (Cf. SILVA, 1994), no nosso entender uma versão atualizada do ditado "está escrito, logo é verdade", ambas emergem da análise das cartas e são, nesse sentido, verdadeiras.

Apresentamos, a seguir, esquematicamente, outros aspectos do documento que serão analisados em detalhe nas próximas etapas desta pesquisa: o uso de abreviaturas, a pontuação e a análise lingüística. Pontuação e abreviaturas formam uma interface entre o formal e o lingüístico e entre o formal e o conteúdo.

\section{d - Abreviaturas}

Há inúmeras abreviaturas: tanto as sistemáticas, isto é, utilizáveis em qualquer palavra, quanto as vocabulares, próprias de cada palavra e não redutíveis a soluções gramaticais. Algumas são decididamente ambíguas, como "a D's", que tanto pode ser uma despedida, "adeus", como "a Deus". Somente o contexto poderá ajudar nessa decifração. Muitas delas são dicionarizadas (Cf. Flechor, 
1991 ), só para citar algumas: q' ("que"); aD's ("adeus"); D’s ("Deus"); I ("irmã"); IAC ("irmã amante, Catarina"); IA ("irmã amante"); CR ("Catarina regina").

Outras são abreviaturas de palavras maiores, tais como: $\mathrm{g}^{\mathrm{de}}$. ("grande"); mª . ("muita"); pte. ("parte"); co. ("com"), etc.

Observem-se alguns contextos:

- Carta 72: "o q' me aconselha o grande cuidado q' me dignificais...", " ...a deshoras as faz com q' eu não viva co mta. quietação...", "...co a grande brevidade..."

- Carta 66: “...dizemme q' ay...q' vão...”, “...não perder ... as esperanças de q' D's ... dê os augmentos q' esta dezeja C.”,

- Carta 1: "...gde. empenho q' tem mostrado...", "... em qto...”

- Carta 8: "I toda V"

\section{e - Pontuação}

Quase não há pontuação nas cartas. O uso de vírgula é o mais comum, em contextos inadmissíveis para a língua contemporânea. O ponto final é o outro sinal gráfico usado. Não há pontos de exclamação, interrogação, ponto-e-vírgula, dois pontos ou reticências. Seguindo Rosa (1994), acreditamos ser a pontuação de relevante interesse para se evidenciar a continuidade/descontimuidade entre constituintes sintáticos em um texto, o que evidentemente contribuirá para a precisão de sua interpretação. Trataremos deste aspecto em outra oportunidade.

\section{f - Aspectos lingüísticos}

Interessa-nos registrar alguns aspectos lingüísticos das cartas, entendidos como representativos da língua portuguesa do século XVII. Reveste-se, portanto, este documento, de importância para o conhecimento da língua portuguesa do século XVII, por ser datado, localizado e por permitir uma caracterização sociolingüística e 
histórica de seu autor, pertencente a uma classe social bem definida: a nobreza.

Limitar-nos-emos, agora, a apontar alguns fatos relevantes.

A presença de espanholismos vem comprovar o bilingüismo de Catarina. Vejam-se:

- muchíssimo; dizemme que ay varias embarcações; adonde; alomenos; ariba; uso do verbo ser em tempos compostos que à época, na língua portuguesa, ou já tinham sido substituídos por ter ou estar, ou usava-se uma forma verbal simples: "o correo não he ainda vindo"; "Manoel Diaz e seus criados são chegados a 20 de fevereiro..."; "Suposto que os correios são bem tardios...".

Destacaremos, na sintaxe, a predominância do uso da próclise, da anteposição do adjetivo qualificativo ao nome que modifica, e a presença de estruturas coordenadas. Registram-se ocorrências da próclise máxima em estruturas negativas, já desaparecida do português contemporâneo:

pág. 1 "...mas certa estou a não representareis..."

pág. 14 "...que lhe não pode ajudar..."

pág. 33 "... me não acaba de restituir de todo a saúde..."

pág. 33 "...para lhe não ser ingrata..."

pág. 52 "...me não allargo mais..."

A coordenação de elementos não-paralelos é também registrada nas cartas:

pág. 56 “... ao grande dezejo q' eu tenho de vos ver e a minha sobrinha..."

pág. 16 "...a el Rey disse q' vos me escrevestes elle estimou muito e a nação..."

A colocação de adjetivos antepostos ao nome é a ordem preferencial, dentre os quais predomina o adjetivo "grande", um padrão arcaizante que não mais prevalece no português contempo- 
râneo, cuja ordem não-marcada para a colocação do adjetivo qualificativo no sintagma nominal é a posposta. ${ }^{2}$

Elementos de oralidade: presença do verbo "cuidar" numa interpolação típica do registro oral e familiar: “... a verdade de meu affecto pa. convosco de q' cuido não duvidas...”; construções de tópico, que apesar de existirem também na língua escrita, caracterizam-se mais como uma marca de oralidade: "Navios, só en hũa noute se perderão dous Inglezes e hũ ollandes...”.

Observa-se ainda, como traço de oralidade, a presença de construções repetitivas, principalmente nos fechos e nas passagens em que Catarina pede notícias do irmão e da família. Tais repetições, que à primeira vista podem empobrecer o documento sob um ponto-de-vista literário, vêm a enriquecê-lo sob uma perspectiva sociolingüística.

Para finalizar, apresentamos a transcrição ${ }^{3}$ e o fac-simile da carta $\mathrm{n}^{\mathrm{o}} 52$.

Transcrição:

Meu Irmão. Não quero deixar passar correo, sem vos segurar que fico, de saude sendo, que neste não vos poderei, dar, essa imformação, pois me continua ainda o mesmo mal do peito, de que, ja em outra vos dei conta, estes dias, me achei delle tão maltratada q' o Doutor Mendez esteve para fazer junta de medicos, para com toda a brevidade me aconsselhar não deixasse correr, nem asentar hu) humor q' he tão ariscado, em hu)a parte tão delicada como o peito, bendito D's ha tres dias q' me acho, com algu)a melhoria, suposto he tão poca q' outra vez me começão a repetir, as picadas o que me faz crer, me apostemara de novo o peito, como ja fez, o que he mais penozo, por ser interior, por esta cauza, como por me dizerem q' nenhu)a carta, vai sem exame me não alargo mais q' vos melhores notiçias tendes q' as minhas pode ser adeus

I. Amante C.

${ }^{2}$ Veja-se COHEN (1986/1989) para análise detalhada da colocação dos adjetivos na história do português, incluindo a do presente documento.

${ }^{3}$ A pontuação original e as abreviaturas são mantidas. 


$$
\ldots+-3 x^{\prime \prime}
$$

t5.

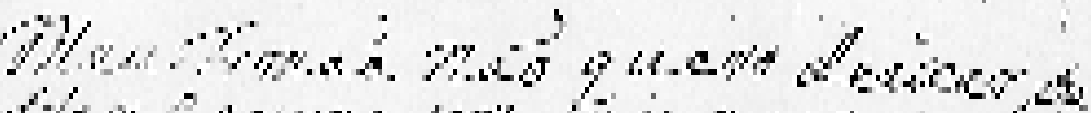

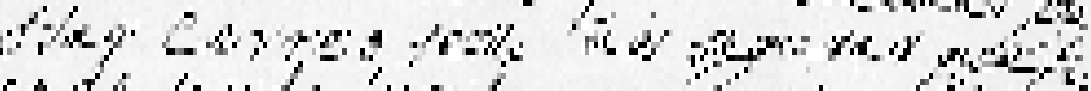

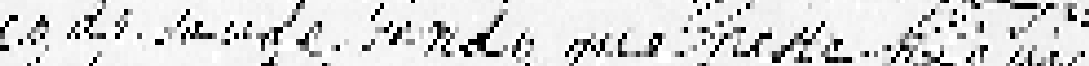

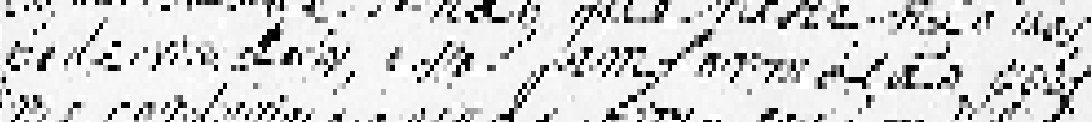

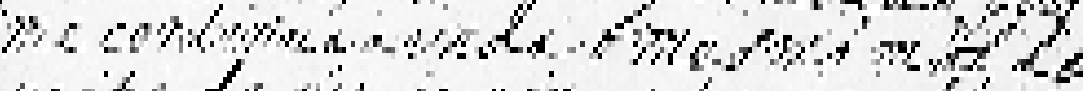

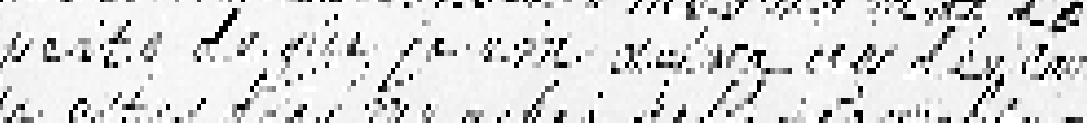
$6, \mathrm{~s}$ -

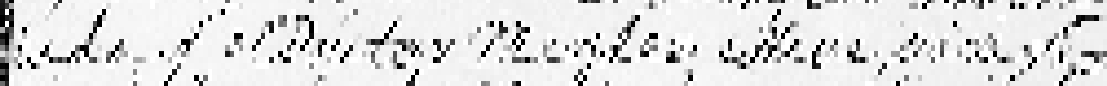

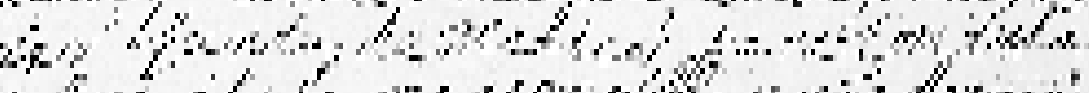

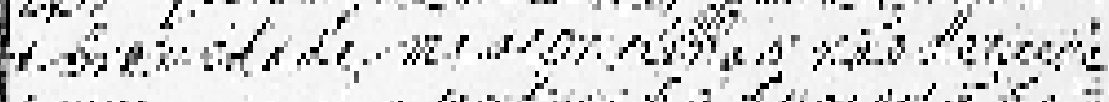

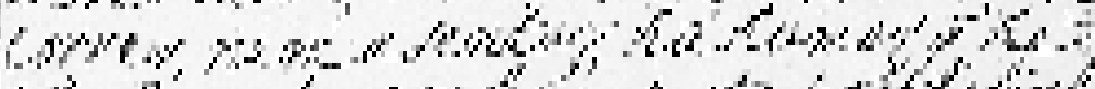

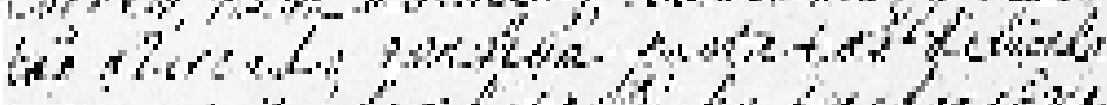

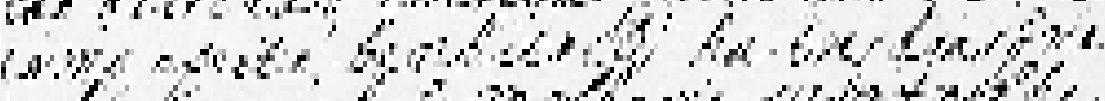

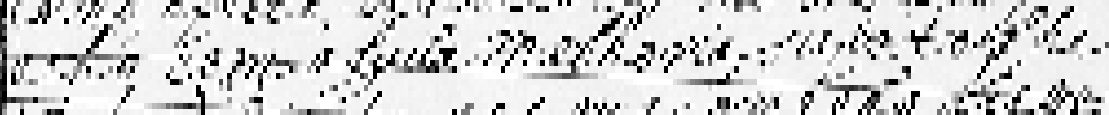

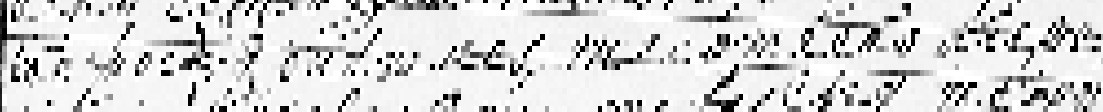

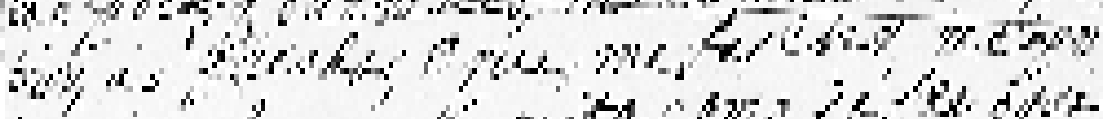

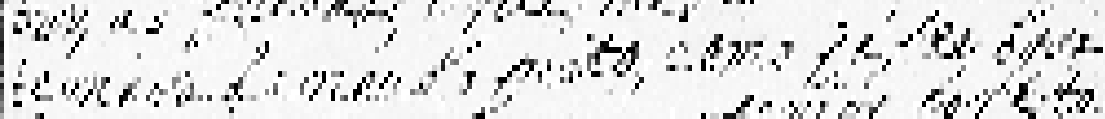

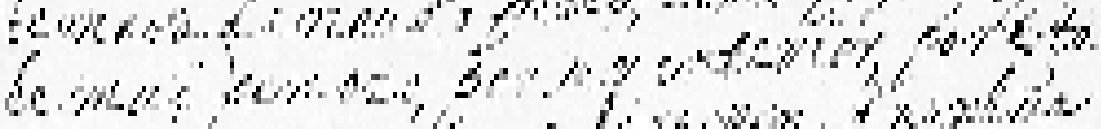

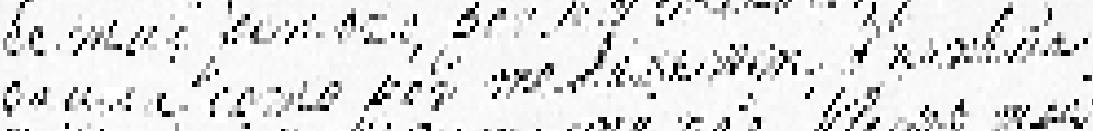

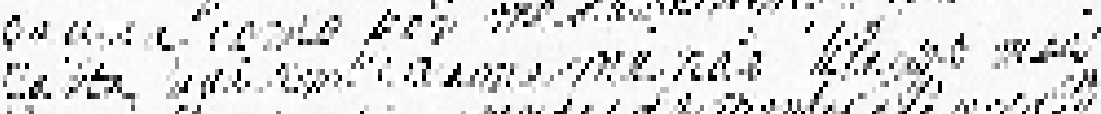

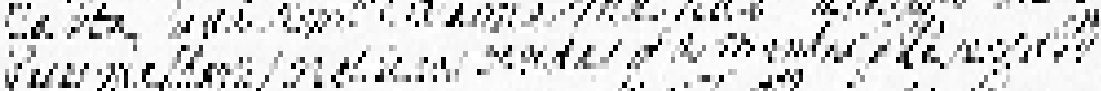

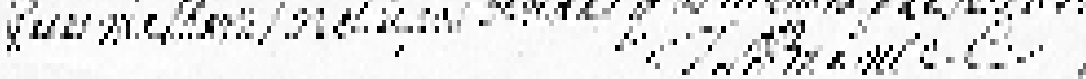




\section{Bibliografia}

AZEVEDO Fơ ${ }^{\circ}$ L. A. de. Iniciação em Crítica Textual. São Paulo: Edusp, Presença, 1987.

BLECUA, Albert. Manual de Crítica Textual. Madrid: Editorial Castalia, 1987.

CASTRO, Ivo. Enquanto os escritores escreverem... Conferência plenária, IX Congresso Internacional da ALFAL. São Paulo: Unicamp, 1990.

COHEN, M. A.A.M. Syntactic Change in Portuguese: relative clauses and the position of the adjective in the Noun Phrase. Tese de doutorado inédita. São Paulo: Unicamp, 1986/1989.

DUARTE, Luiz F. Prática de edição: onde está o autor? Gênese e Memória - IV Encontro Internacional dos Pesquisadores do Manuscrito e de Edições. São Paulo: Annablume, 1994.

FIGANIÈRE, Francisco de la. Catálogo Dos Manuscriptos Portuguezes existentes no Museu Britânico. Lisboa, 1853.

FLECHOR, Maria Helena Ochi. Abreviaturas - dos séculos XVI ao XIX. São Paulo: Ed. Unesp, Secretaria de Estado da Cultura, Arquivo do Estado de São Paulo, 1991.

FRANÇON, A. \& GOYARD, C. Les Correspondances Inèdites. Paris: Ed. Economica, 1984.

HOUAISS, A. Elementos de Bibliologia. Rio de Janeiro: INL, 1976. 2v.

LAUFER, Roger. Introdução à Textologia. São Paulo: Perspectiva, 1980.

LIVERMORE, H. V. A History of Portugal. London: Cambridge University Press, 1947.

MIAZZI, Maria Luísa Fernandez. Introdução à Lingüistica Românica. São Paulo: Cultrix, 1976.

NUNES, E. Borges. Abreviaturas Paleográficas Portuguesas. 3. ed. Lisboa: [s.e.], 1981. 
PEARSON, Hesketh. Charles II, his life and likeness. London: Heinemann, 1960.

ROSA, Maria Carlota. Pontuação e sintaxe em impressos portugueses renascentistas.Tese de doutorado, Rio de Janeiro: UFRJ, 1994.

SERRÃO, Joaquim Veríssimo. A Historiografia Portuguesa. v.2. Lisboa: Verbo, 1973.

SERRÃO, Joel. Dicionário de História de Portugal e do Brasil. Porto: Ed. Figueirinhas, s/d.

SILVA, Antônio Franco Ribeiro da. As cartas não mentem jamais. $O$ desejo de Freud. São Paulo: Iluminuras, p.137-165.

SPINA, Segismundo. História da Lingua Portuguesa III: Segunda metade do século XVI e século XVII. São Paulo: Ática, 1987.

SPINA, Segismundo. Introdução à Edótica. São Paulo: Cultrix, 1977.

TOVAR, Pedro. Catalogo dos Manuscriptos portugueses ou relativos a Portugal existentes no Museu Britânico. Coimbra, 1932.

WILLEMART, P. Gênese e Memória - IV Encontro Internacional dos Pesquisadores do Manuscrito e de Edições. São Paulo: Annablume, 1994.

\section{Resumo}

Apresenta-se, neste artigo, um documento inédito português do século XVII. De sua análise emergem a personagem histórica e a figura humana e feminina de Catarina de Bragança. Seu valor como fonte para pesquisa da língua portuguesa do século XVII é também estabelecido.

\section{Abstract}

In this article, an unpublished 17th century portuguese manuscript is presented. Both the historical character and the human figure of Catarina de Bragança are brought up by its analysis. Its value as a source of the 17 th century portuguese language is also established. 